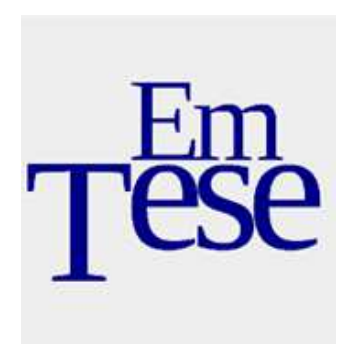

\title{
Teorias críticas da juventude: geração, moratória social e subculturas juvenis
}

\author{
Luís Antonio Groppo ${ }^{1}$
}

\section{Introdução}

Ao longo do século XX e no início do XXI, as ciências humanas e psicológicas constituíram diversas teorias e concepções sobre a juventude que passaram a considerar mais os fatores sociais e culturais. Tomando de empréstimo os termos que Tomaz Tadeu da Silva (2010) utilizou para descrever a trajetória das teorias do currículo, creio que podemos classificá-las em teorias tradicionais, críticas e pós-críticas da juventude, conforme definições melhor expostas adiante.

Neste artigo, pretendo desenvolver considerações a respeito das teorias críticas da juventude, focando elementos que marcaram a trajetória desta categoria nas ciências sociais, especialmente na chamada sociologia da juventude. Elementos, em especial as noções de geração, moratória social e subculturas juvenis, que influenciaram visivelmente as maneiras como Estado, sociedade e movimentos sociais conceberam e concebem a juventude.

Entre as teorias tradicionais da juventude, que se desenvolveram ao longo da primeira metade do século XX, se tornaria hegemônica a versão estrutural-funcionalista, a qual considera que os grupos juvenis têm a função de socialização secundária, destacando-se Parsons (1968), Coleman (1961) e Eisenstadt (1976). O estruturalfuncionalismo se preocupa com a integração do indivíduo em uma estrutura social que

\footnotetext{
${ }^{1}$ Professor da Unifal-MG (Universidade Federal de Alfenas). Pesquisador do CNPq. Doutorado em Ciências Sociais pela Universidade Estadual de Campinas (2000). Mestrado em Sociologia pela Universidade Estadual de Campinas (1996). Possui graduação em Ciências Sociais pela Universidade de São Paulo (1992). Contato: luis.groppo@gmail.com.
} 


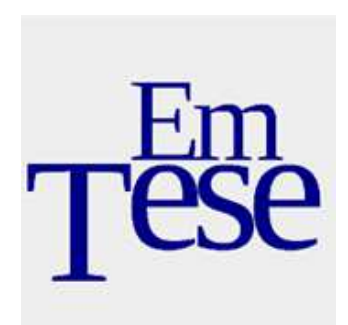

não é posta em causa por esta corrente teórica. Dos jovens é que vem o risco da "anormalidade" e desvio, em especial desde a delinquência dos novos - tema destacado das pesquisas de campo das teorias tradicionais da sociologia da educação.

A segunda metade do século XX iria desenvolver de modo mais característico teorias críticas, tema deste artigo. As teorias críticas não contestam uma ideia básica da sociologia estrutural-funcionalista: a juventude como socialização secundária. Mas contestam os sentidos tradicionais desta vinculação dos indivíduos à estrutura social, tendendo a valorizar a participação dos jovens nas transformações sociais.

Já as teorias pós-críticas, tema para próximos estudos, desenvolvidas desde o final do século XX, encaminham a sociologia da juventude para uma posição "pósmoderna", cada vez mais relativizando e até negando a proposição original das teorias tradicionais - a juventude como transição à vida adulta, por meio da socialização secundária. Entre os autores que mais influenciaram esta posição podem ser citados Maffesoli (1987) e Baudrillard (1972).

As primeiras teorias críticas da juventude nasceram em meados do século passado, quando a variante estrutural-funcionalista era hegemônica na nascente sociologia da juventude. Estas primeiras teorias críticas combinaram, em diferentes ênfases, conforme o autor, a noção de geração e a noção de moratória social. O traço crítico destas teorias que abordam a geração e a moratória reside no fato de que tendem a reconhecer o papel das juventudes na transformação social e atribuem um sentido positivo a este papel. Como se verá, entretanto, libertam-se pouco da concepção "naturalista" de juventude. E o reconhecimento do potencial transformador das jovens gerações não as levam a uma posição radical, mas mais caracteristicamente reformista, desconfiando mesmo dos movimentos juvenis que abundariam nos anos 1960.

Por sua vez, as teorias críticas que se desenvolvem ao longo dos anos 1960 tendem a uma posição politicamente mais revolucionária. Mas a característica principal delas é a relação mais contundente que fazem entre a estrutura socioeconômica e a experiência da juventude. Algumas vezes, chegaram ao extremo de negar relevância 


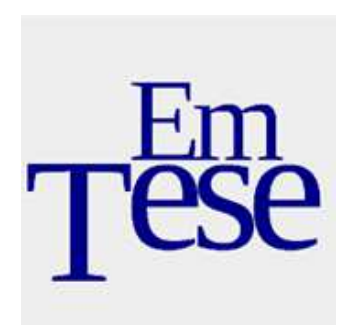

sociológica à noção de juventude. Normalmente, entretanto, relativizam esta noção, demonstrando os inúmeros modos de vivê-la, incluindo grupos (como as camadas populares e as mulheres) que enfrentam a negação total ou parcial do direito de viver a juventude.

\section{Geração}

O sociólogo húngaro, radicado na Inglaterra desde a ascensão do nazismo, Karl Mannheim, aproximou-se do tema das gerações a partir da sociologia do conhecimento, em sua busca de compreender as dinâmicas de construção e transmissão social do conhecimento. Deste modo, Mannheim e a sua sociologia da juventude inserem-se no que Pais (1993) denominou de "corrente geracional" dos estudos sociológicos sobre os jovens, ao lado do estrutrual-funcionalismo ("teoria da socialização"). Ambas as teorias, a estrutural-funcionalista e a "teoria das gerações" de Mannheim, voltam-se ao tema das continuidades e descontinuidades intergeracionais, e ambas tendem a uma concepção de fundo "naturalista" (bio-psicológico) de juventude. Entretanto, Mannheim distingue-se do estrutural-funcionalismo por sua ênfase no potencial transformador da juventude, visto como algo positivo, não como desvio, disfunção ou perigo, e por isto o incluo entre o que chamo de teorias críticas.

Apesar do texto de Mannheim sobre as gerações ser original de 1927, estas suas ideias ganhariam força no interior da sociologia apenas na década de 1950 (MURDOCK; MCCRON, 1982), em meio ao auge do estrutural-funcionalismo, mas logo servindo como alternativa a ele.

Fonte fundamental da sociologia de Mannheim é a obra de Max Weber, que fornece importantes conceitos, tal como o de situação social. Para Mannheim, a geração é um tipo de situação ou posição social. A geração não é um grupo social concreto, como é a família, tribo ou seita. É, assim como a classe social, uma situação social. Não é automático e necessário que indivíduos em dadas situações sociais (como classe e 


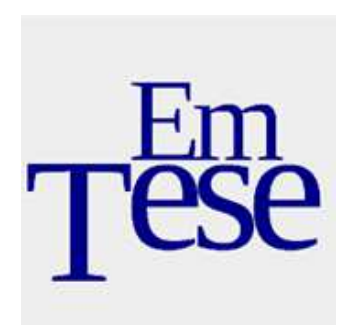

geração) formem grupos sociais concretos (como, no caso das classes operárias, partidos, sindicatos e movimentos operários). Isto é apenas uma potencialidade. Se classe social e geração, ambas, são situações sociais, ou seja, são condições formalmente análogas, elas são muito diferentes do ponto de vista dos seus conteúdos. A classe social se define pela situação em comum de certos indivíduos no interior das estruturas econômicas de uma sociedade. Já a geração se define pelo fato de que certos indivíduos com idades semelhantes viveram em sua juventude (período crucial no curso da vida pessoal) "uma situação comum no processo histórico e social" (MANNHEIM, 1982, p. 72). Essa situação social, que define a geração, estabelece uma gama mais ou menos restrita de experiências sociais em comum àqueles indivíduos e encaminha-nos a certo tipo de ação social.

Se uma geração vivesse para sempre, sem necessidade de outra para substituí-la, não haveria o problema da integração social (SOUSA, 2006). E a transformação social figuraria a esta geração eterna de modo completamente diferente. Entretanto, sempre aparecem novos participantes da vida social, enquanto outros desaparecem. Como já dito, membros de dada geração participam de seção limitada do tempo histórico. Como se acrescenta agora, a transmissão da herança cultural e a transição de uma geração a outra é um processo contínuo: não é marcada por uma ruptura bem estabelecida no tempo. Mas isto, na verdade, não caracteriza necessariamente todas as sociedades. Como ilustra Morin (1986), as sociedades modernas não possuem significativos ritos de passagem, que marcam claramente a passagem de um grupo etário a outro: vai se "adolescendo" e "amadurecendo" gradativamente. Já as sociedades tribais que realizam os ritos de iniciação, parecem criar dobraduras no curso da história de uma geração ou grupo de idade, para demarcar muito bem a passagem de uma condição etária a outra (GENNEP, 2011).

A juventude é tida para Mannheim como momento crucial da vida, já que é neste período que os sujeitos adquirem "padrões inconscientemente 'condensados"” (MANNHEIM, 1982, p. 78), um fundo de experiências sociais que, pela primeira vez na 


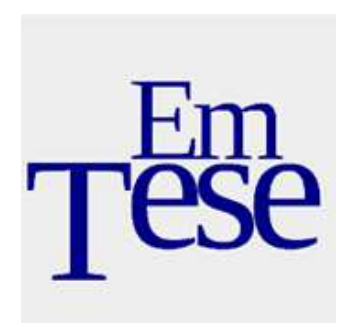

vida, são conscientemente recebidas. Estes padrões ou quadro de referências se torna a base sobre a qual futuras experiências sociais serão avaliadas pelo indivíduo. A juventude é assim concebida como fase da vida em que há uma vinculação experimental com a realidade e os valores sociais, contrastando com a maturidade, quando o indivíduo julgará novas experiências sociais com base nestes padrões já sedimentados, de modo mais racional e reflexivo. É por isto que o adulto tende a ser mais resistente à mudança social, pois aceitá-la pode significar a contestação de seus próprios quadros arraigados de referência pessoal e coletiva.

Há também um fundo "naturalista" na concepção de juventude e geração em Mannheim. Trata-se da idade e do grupo etário concebidos como dados "naturais", simplesmente biológicos do curso da vida. Talvez, pudesse Mannheim desnaturalizar mais as suas noções. Contribuiria para isto o próprio confronto com a visão estruturalfuncionalista de juventude de Eisenstadt (1976): para Eisenstadt, a juventude se define como grupos etários homogêneos, que não são algo natural e generalizado em todas as sociedades e períodos históricos, mas sim uma função destinada a contribuir para a integração social em sociedades de tipo "universalista" - tal qual a moderna. Esta experiência geracional significativa é, ela própria, uma construção social e histórica, possibilitada por dada configuração das sociedades nas quais os grupos etários homogêneos, como os juvenis, são importantes. E não o inverso, como insinua Mannheim, em que um dado "natural" do curso da vida, a vinculação experimental com a realidade no período juvenil, é uma força potencial de transformações que pode ou não ser mobilizada pela sociedade.

Valem ao menos dois comentários, a princípio. Primeiro, sobre as características atribuídas por Mannheim às idades da vida: infantes com relação não consciente com os valores e realidades sociais, jovens experimentando este mundo como um livro aberto, contraditório e contestável, e adultos avaliando racionalmente os novos fatos com base nos padrões sedimentados em suas consciências. Estas características parecem universais e até naturais, mas na verdade correspondem a uma dada vivência das idades 


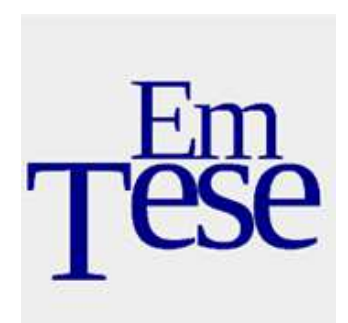

da vida, típicas de certas sociedades e certo tempo histórico: o mundo ocidental "desenvolvido" em meados do século XX. Mais, parecem ligados a uma "ideologia" sobre as idades da vida, que carrega um ideal de sociedade e de curso da vida. Esta ideologia reconhece a forte descontinuidade histórica, em sociedades modernas que vivem em constante transformação, dificultando a transmissão dos valores e padrões sociais entre as gerações. Ao mesmo tempo, tal ideologia concebe de modo linear e acumulativo as experiências vividas em diferentes fases da vida, indo da menor racionalidade na infância ao domínio sóbrio e lógico do mundo pela maturidade. Ver-seá na psicanálise de Erik Erikson, adiante, uma influente sistematização desta concepção linear do curso da vida, tão marcante no corpo ideológico da modernidade.

A maior contribuição de Mannheim em relação ao ideal de desenvolvimento humano da modernidade está na defesa do potencial renovador da sociedade contido na juventude. Segundo Mannheim, a geração jovem vive um "contato original”, primeiro, com a herança cultural que lhe é apresentada, contato que pode se caracterizar como um relacionamento modificado e um distanciamento em relação a esta herança oferecida. $\mathrm{O}$ contato original, esta "experiência", é algo fundamental na formação da identidade individual, como visto. Mas é também algo fundamental para a dinâmica da sociedade, um canal de introdução de mudanças. O contato original dos jovens com a cultura, por se dar de modo diferenciado do que fizeram, quando jovens, as gerações anteriores, pode levar estes moços a uma maior receptividade em relação a novos valores, hábitos e atitudes, por vezes assumidos de modo radical. Na relação entre as gerações, segundo Mannheim, cabe a mais jovem comunicar o novo às mais velhas, ainda que por meio do atrito e do conflito (SOUSA, 2006).

Assim, se as jovens gerações, como desvantagem, não podem absorver, "voluntária e completamente, o conjunto de conteúdos acumulados de sua cultura, que são o suporte para a estabilidade das gerações anteriores”, elas têm uma grande vantagem: a de “[...] poder avaliar o 'inventário cultural' disponível, que pode tanto ajudar a esquecer o que já não é mais útil quanto desejar o que ainda não foi 


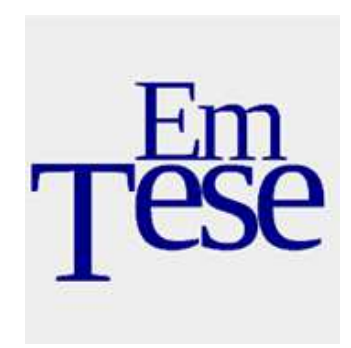

conquistado" (SOUSA, 2006, p. 10).

Há ainda uma segunda fonte do interesse de Mannheim sobre a juventude, ao lado do tema da transmissão social do conhecimento que o levou ao estudo das gerações. Tema que reforça a caracterização da juventude como mecanismo de mudança social. Trata-se da constituição de uma "Terceira Via", política e ideológica, distinta do liberalismo e do totalitarismo, em tempos da Segunda Guerra Mundial. Mannheim, judeu, havia se refugiado na Inglaterra, e de lá se tornou um importante sistematizador de uma corrente ideológica que ajudaria a criar, no pós-Guerra, o clima político favorável ao Estado de Bem-Estar e ao planejamento social, para a reconstrução do mundo europeu destroçado pelo confronto. No que se refere à juventude, destaca-se uma das conferências publicadas em Diagnóstico de nosso tempo (MANNHEIM, 1961), também presente na clássica coletânea Sociologia da Juventude, organizada por Sulamita Britto (MANNHEIM, 1968).

Na conferência feita na Inglaterra, a juventude é apresentada como "reserva vital" da sociedade, parte de suas energias latentes, que podem ser mobilizadas em sociedades em transformação. Esta mobilização deveria se dar por meio da "integração" (ou organização em prol de uma meta) destas energias latentes, por meio da transformação da reserva vital em "função".

A juventude é considerada como agente revitalizador, fonte de energia renovadora da sociedade, dado seu vigor e seu menor enredamento na ordem social vigente. Ela chega vindo como de fora e encara uma sociedade britânica, então, em situação caótica e conflituosa. Os jovens estariam em situação de relativa marginalidade, na posição de estranhos ou estrangeiros, numa verdadeira posição social liminar que, mais do que fatores biopsicológicos, determinaria a condição juvenil. Neste momento, Mannheim avança um pouco mais em relação à desnaturalização das categorias etárias, mais do que fez em relação à noção de geração.

Diante desta novidade, a realidade social exposta em seus fundamentos, para além do restrito mundo doméstico, os jovens podem levar a solidarizar-se com 


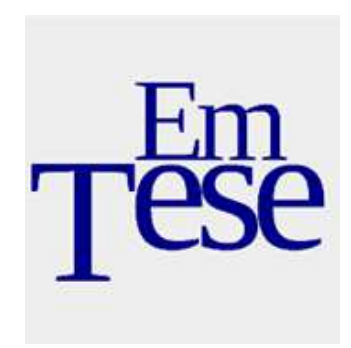

movimentos sociais insatisfeitos com a ordem social dada. Afinal, jovens gerações, movimentos sociais e intelectuais "alternativos" estariam, como diria Bourdieu (1984), em posição homóloga diante dos valores legitimados pela ordem social, ou seja, em posição marginal.

Após ter retomado essa idealização da juventude aventureira, imersa no tempo presente e na espontaneidade, Mannheim reclama faltar à Inglaterra de então, função reconhecida para a participação dos jovens na vida pública. Esta desmobilização até seria correta em sociedades tradicionais, contra mudanças, que precisam neutralizar a potencialidade dos jovens, algo feito outrora na Inglaterra por meio do prestígio total concedido aos mais velhos (o que também deve ter levado os jovens a adotar atitudes e consumir produtos que os fizessem parecer anciãos, tal como os jovens da elite brasileira no início do século passado, segundo Debert [2010]) e a ausência de associações e movimentos juvenis espontâneos. Os grupos juvenis espontâneos, tal qual o Movimento Juvenil Alemão do início do século XX, que certamente Mannheim tem em mente, eram cultivadores do espírito de solidariedade e da vida em grupo que tanto contrastavam com o egocentrismo, isolamento e sofrimento do indivíduo num mundo dominado por grandes organizações impessoais e de normas abstratas.

Como se pode perceber por outros textos de Diagnóstico de nosso tempo (MANNHEIM, 1961), o sociólogo alemão caracteriza o mundo ocidental de então do seguinte modo: as transformações abruptas promovidas pela racionalidade técnica, que romperam com as formas de vida comunitária e tradicionais, jogaram os indivíduos na solidão, à mercê por vezes de movimentos totalitários que prometem algum sentido e segurança à "multidão solitária". Isto explica o sucesso e o avanço do totalitarismo, como o nazismo na Europa Central. E também o fracasso das sociedades que desejam manter o "liberalismo" como forma de organização social e econômica. Haveria de se constituir uma "terceira via" para preservar o que restava de liberdade e democracia, o “planejamento democrático". Nem o mundo econômico à mercê do livre mercado, nem a tolerância liberal omissa diante dos inimigos da liberdade, nem a democracia 


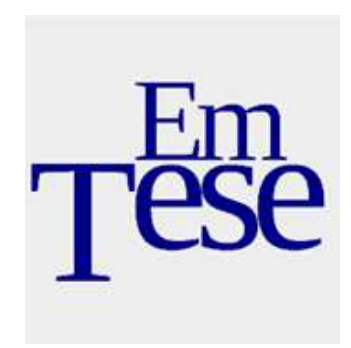

meramente representativa.

Na conferência relativa à juventude, Mannheim destacou a necessidade de uma democracia militante na Inglaterra, para a qual a juventude deveria se tornar a sua "força desbravadora" (1968, p. 87). As energias latentes da juventude inglesa deveriam ser integradas nacionalmente, orquestradas em prol da necessária mudança de mentalidade no país, levando mesmo o jovem inglês a agir como pioneiro externamente. É algo semelhante ao que fizeram os países ditos totalitários que, de algum modo, perceberam a função social da juventude em uma sociedade dinâmica. Mas deveria ser feita a mobilização juvenil por uma terceira estratégia, distinta da omissão liberal e da manipulação nazista. Esta terceira solução é reformista, comedida até, mantendo boa parte do sistema educacional inglês e do movimento juvenil como estavam. E, diferente do totalitarismo, valorizaria a solidariedade e a cooperação, em vez da cega obediência.

Diferente do liberalismo, não seria neutra, mas sim ativa e militante na defesa dos valores básicos comuns.

Após desenvolver a noção sociológica de gerações, Mannheim, de modo semelhante ao que já fizera o estrutural-funcionalismo, esboça o que seria a moratória social, pretensa condição da juventude no mundo moderno: separação relativa dos jovens do mundo adulto e público para o aprendizado de hábitos e valores básicos, que os predisponham a assumir papéis sociais requeridos pela sociedade quando se tornarem adultos. Entretanto, Mannheim acrescenta um novo elemento neste esboço da moratória social, noção que ainda não foi nominada explicitamente: seria um tempo permitido para experiências, inovações, contatos com alternativas no que se refere a valores sociais, hábitos e atitudes, que permitiriam ensaios e erros importantes não apenas aos sujeitos jovens, mas para a própria renovação da sociedade, quando isto se demonstrar necessário. Entretanto, tal noção, a de moratória social, seria desenvolvida nos anos seguintes, a partir da psicanálise. 


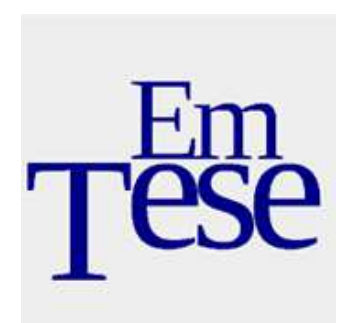

\section{Moratória social}

É certo que o estrutural-funcionalismo havia esboçado a noção de moratória social, especialmente quando concebeu as funções da separação, no tempo e no espaço, dos jovens em escolas de ensino médio (PARSONS, 1968; COLEMAN, 1961). Mannheim herdou algo desta tradição, o que já se insinua no uso do termo "função" em sua conferência sobre a mobilização dos jovens ingleses em prol da democracia militante. Mas ele não se limita a descrever dada realidade social. Esta conferência é explicitamente prescritiva, tem caráter dramaticamente político. Indica-se, então, em relação à tese da moratória social da juventude, que os sociólogos que a constroem, mesmo sem fazer uso do termo, como Karl Manheim, ao lado de psicólogos como Erik Erikson (que fez uso corrente dele), não apenas detectam um dado elemento da realidade social. Eles também contribuem para sua construção, reconhecimento e legitimidade. Textos característicos dos anos 1960, quando a moratória social é conformada como ideia descritiva e conceito prescritivo, têm este caráter ambíguo, misto de ciência e política, tal qual Diagnóstico de nosso tempo de Mannheim.

Não é o caso do livro mais conhecido do psicanalista norte-americano Erik Erikson, Childhood and society (ERIKSON, 1978), mas o é de outra obra, publicada no explosivo ano de 1968, que trata especialmente da juventude (ERIKSON, 1987). Erikson praticou clínica na Áustria com Ana Freud e buscou desenvolver as concepções dela e de seu pai, Sigmund Freud, sobre infância e desenvolvimento humano, em diálogo com outras tradições da psicologia. Apesar de pertencer a outro campo de estudos, Erikson interessa à sociologia da juventude, assim como o psicólogo G. Stanley Hall (1937), pela influência de suas ideias para além dos chamados campos "psi”. Isto se deve especialmente à noção de moratória psicossocial de Erikson, mas também decorre de sua busca de combinar aspectos biopsicológicos e sociais na sua concepção do desenvolvimento humano.

Com Erikson, a psicanálise se volta às idades da vida. Encontra, em terreno 


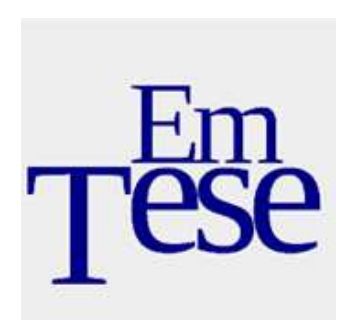

intermediário entre o biológico, o psíquico e o social, lugar fecundo para pesquisar, pensar e propor a respeito do curso da vida individual. Childhood and Society, publicado originalmente em 1950, foi um grande sucesso editorial, destacando a infância, mas também tratando da juventude norte-americana, da infância e adolescência de Adolf Hitler (e o contexto alemão) e da juventude de Maxim Gorky (e o contexto russo). Segundo A. M. Corzos, nesta obra Erikson "introduz sua concepção de um desenvolvimento psicológico que evolui de modo epigenético, isto é, com uma sequência e vulnerabilidade predeterminada, a qual se vê contraposta com a influência exercida pela realidade social sobre o indivíduo" (apud ERIKSON, 1987, p.1, grifos do original). Erikson concebe 8 "idades do homem", sintetizadas em uma "carta das idades do homem", ou "carta epigenética", exposta em forma de tabela. Cada idade inclui zonas e modos pregenitais e genitais, cada qual com seu próprio conflito, cuja resolução gera uma nova qualidade adquirida pelo Ego na sua relação com a sociedade. A carta, simplificada, está exposta na tabela 1.

Tabela 1: Carta das idades da vida segundo Erik Erikson

\begin{tabular}{|c|c|c|c|}
\hline Fase & Modo & Conflito & $\begin{array}{l}\text { Qualidade } \\
\text { adquirida }\end{array}$ \\
\hline Fase I: $1^{\mathrm{a}}$ infância & fase sensor anal & $\begin{array}{l}\text { confiança básica } \\
\text { versus falta de } \\
\text { confiança }\end{array}$ & confiança básica \\
\hline Fase II: $2^{\mathrm{a}}$ infância & fase muscular anal & $\begin{array}{l}\text { autonomia versus } \\
\text { vergonha e dúvida }\end{array}$ & autonomia \\
\hline $\begin{array}{l}\text { Fase III: } \quad 3^{\mathrm{a}} \\
\text { infância }\end{array}$ & $\begin{array}{l}\text { fase locomotora- } \\
\text { genital }\end{array}$ & $\begin{array}{l}\text { iniciativa versus } \\
\text { culpa }\end{array}$ & iniciativa \\
\hline Fase IV: latência & latência & $\begin{array}{l}\text { industriosidade } \\
\text { versus inferioridade }\end{array}$ & industriosidade \\
\hline $\begin{array}{ll}\text { Fase } & \text { V: } \\
\text { adolescência }\end{array}$ & puberdade & $\begin{array}{l}\text { identidade versus } \\
\text { confusão de papeis }\end{array}$ & identidade \\
\hline $\begin{array}{l}\text { Fase VI: jovem } \\
\text { adulto }\end{array}$ & juventude & $\begin{array}{l}\text { intimidade versus } \\
\text { isolamento }\end{array}$ & intimidade \\
\hline $\begin{array}{l}\text { Fase VII: idade } \\
\text { adulta }\end{array}$ & adulto & $\begin{array}{l}\text { generosidade versus } \\
\text { estagnação }\end{array}$ & generosidade \\
\hline $\begin{array}{ll}\text { Fase } & \text { VIII: } \\
\text { maturidade } & \end{array}$ & maturidade & $\begin{array}{l}\text { integração do Ego } \\
\text { versus desespero }\end{array}$ & $\begin{array}{l}\text { integração } \\
\text { Ego }\end{array}$ \\
\hline
\end{tabular}




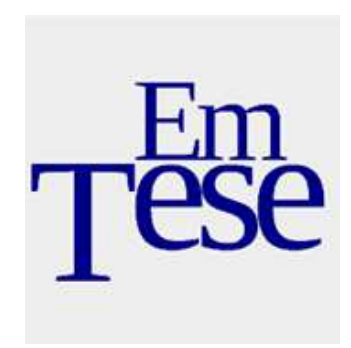

Fonte: Erikson (1978, p. 270, figura 17).

Não se deve negar a tentativa de sofisticação de Erikson em seu esquema, pois combina a evolução linear com a dialética, ao estabelecer que o desenvolvimento do Ego se dá por etapas caracterizadas por um conflito básico e próprio. Também, busca relacionar o determinismo biopsicológico com a influência social, em que ocorre uma dramática série de irrupções das qualidades supostamente universais do Ego no confronto entre indivíduo e sociedade. Entretanto, neste movimento, o psicanalista demonstra menos padrões e instituições universais e revela mais a ideologia da sociedade norte-americana, ou seja, os valores então adotados por esta sociedade e as instituições consideradas importantes, bem como o papel de cada instituição. Revela-se também a concepção linear e acumulativa de capacidades pessoais, que neste momento a cultura e a sociedade "ocidental" moderna geraram, mas estas qualidades são interpretadas como universais, ou ao menos potenciais de qualquer ser humano.

Em Identity, Youth and Crisis, fruto de conferências e originalmente publicado em 1968, ano de intempestivos movimentos estudantis e contraculturais em diversos pontos do globo, Erikson (1987) afirma ser a "identidade" o principal dilema de nossos tempos - enquanto a sexualidade era a grande questão nos tempos de Freud. Os conflitos internos enfrentados pelos "adolescentes" e sua relação com as instituições sociais eram o ponto principal a ser debatido entre os especialistas em desenvolvimento humano. Contra o perigo da "confusão de papeis" se sobrepor à constituição da "identidade", Erikson propõe o reconhecimento de algo que a própria sociedade, em sua sabedoria, vinha constituindo: a moratória psicossocial, direito de adolescentes e jovens no mundo contemporâneo. Esta moratória seria um lapso de tempo para que os sujeitos em constituição de suas identidades pudessem ensaiar e errar, experimentando diversos papéis. Tempo em que haveria um relaxamento ou relativização da aplicação das normas sociais em relação ao comportamento juvenil (KRAUSKOPF, 2004).

A moratória psicossocial coloca os jovens em uma condição de liminaridade em 


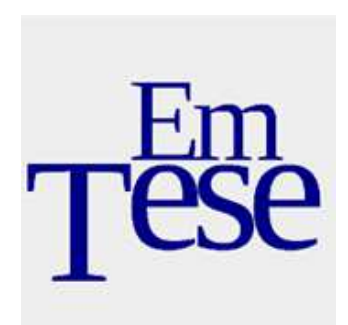

relação à sociedade moderna. Isto já havia sido exposto por Karl Mannheim, que indicara que esta liminaridade permitia aos jovens o estranhamento das normas e valores vigentes (PEREGRINO, 2011). A tese da moratória social encontra um lugar e tempo mais ou menos à margem dos espaços e rotinas oficiais do mundo público para a saudada experimentação de papéis pelos jovens. A moratória social oficializaria a condição liminar da juventude, já reconhecida outrora por Mannheim. Encontrava um correspondente estrutural e funcional, no corpo da sociedade, para o que as sociedades tribais ritualizavam. Van Gennep (2011) descreve as três dinâmicas inscritas nos rituais de passagem: ritos de separação, ritos de incorporação e, entre eles, o estado de liminaridade ou margem. Justamente os rituais de iniciação, como aqueles que marcam a transição pelo sujeito da infância à maturidade plena, são os que mais enfatizam o estado liminar, por vezes fazendo com que o será iniciado passe longo período nesta condição de margem - em local separado do restante da tribo, com regras e tabus específicos, em analogia com a dita moratória psicossocial da juventude na modernidade.

A concepção de moratória psicossocial de Erikson parecia um brilhante projeto civilizatório. Ela expressava uma torrente mais ampla de desejos e interesses, os quais se podem vislumbrar em vários outros autores da época, também moderados politicamente e desconfiados dos movimentos juvenis. Podem ser citados o psicólogo norte-americano Paul Goodman (1971) e o educador e moralista suíço Pierre Furter (1967). Eles também, cada qual ao seu modo, tratam da ideia de se reservar à juventude tempo e lugar para experimentação, bem como a ideia de relaxamento das regras e exigências. E também expressaram suas preocupações em relação à falta de recursos oficias e canais institucionais para dar vazão àquela irrupção de energias destrutivas nos movimentos juvenis. Até mesmo alguns autores marxistas, diante destes movimentos, como Eric Hobsbawm (1982), adotaram algo desta preocupação com os sentidos "anárquicos" e destruidores dos "imaturos" que protagonizavam aqueles protestos.

Mas desde logo, estes desejos e interesses conscientes ou inconscientes da 


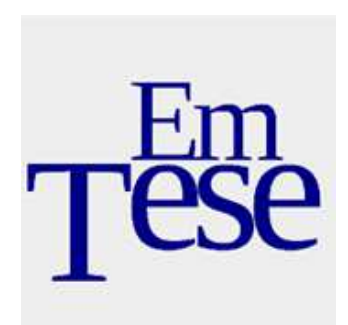

sociedade "oficial" que se expressavam nesta concepção foram alvo de críticas e denúncias. Segundo Kruskopf (2004), a tese da moratória social escondia, sob a roupagem do cuidado e espaço de criatividade, a negação do exercício pelos jovens de verdadeiros papéis como sujeitos sociais, já que aí eram considerados como "imaturos". Também, tendia a provocar a invisibilidade das ações dos jovens ou, quando estas ações se tornavam visíveis, tendia a tachá-las como "perturbação da ordem”. A moratória seria menos uma "sabedoria social" e mais uma "postergação das possibilidades de participação" dos jovens dada a estrutura rígida ocupacional e educacional que vigorava (2004, p. 28).

$\mathrm{Na}$ verdade, desde muito cedo diversos intelectuais fizeram a crítica à tese da moratória social, segundo Krauskopf (2004). Mas é preciso lembrar que esta crítica também foi feita já nos anos 1960 por universitários - tanto discentes quanto jovens docentes - como aqueles que em Maio de 68 denunciaram, ao seu modo, a balela desta moratória, o aspecto segregacionista e desigual da separação entre crianças/jovens ("os que nada sabem") e adultos ("que tudo sabem"), em destaque na educação (NATANSON, 1968). Assim, a própria juventude mobilizada em 1968 expressou, de modo contundente, sua insatisfação contra as muitas formas de dominação existentes, entre as quais aquelas de cunho geracional. Dentro dela chegou a ser proposto, em destaque nos movimentos na Itália e França, a "auto-educação", o "poder estudantil” e a autogestão na educação. Versões mais moderadas recriaram a ideia da cogestão, e ambos, moderados e mais radicais, falaram também da "educação permanente", para toda a vida, assim como a importância maior da disposição constante ao aprendizado (o “aprender a aprender”) em relação ao conteúdo por si só (GROPPO, 2006).

Outros autores, entretanto, têm apontado que um olhar mais matizado sobre a noção de moratória social pode encontrar aspectos positivos, sem deixar de reconhecer seus limites. Um exemplo é Mônica Peregrino (2011), com base principalmente na obra de Margulis e Urresti (1996).

A definição de juventude adotada por Margulis e Urresti (1996) reconhece a 


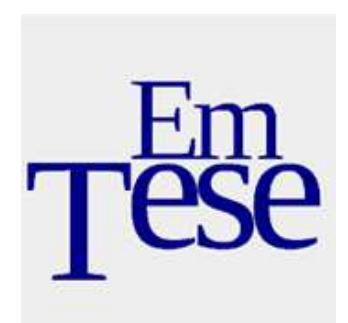

centralidade da experiência da moratória social, a qual, certa época histórica, certos lugares e certas classes sociais puderam oferecer aos seus adolescentes, que viveram então a condição juvenil. A época, a partir do século XIX. Lugares, o mundo europeu e norte-americano, expandindo-se paulatinamente em outros locais tocados pela modernização. Classes, especialmente as elites, depois as classes médias. Mais tarde, e precariamente - em certos lugares, nunca - as classes populares. A moratória social torna-se um período da vida em que se permite postergar diversas exigências sociais tais como trabalho, matrimônio, ter filhos e formar o próprio lar - e em que há uma especial tolerância para com o comportamento juvenil.

Margulis e Urresti acrescentam, na sua concepção de juventude, a "moratória vital". Afirmam que concepções culturalistas tenderam a um extremo relativismo na definição de juventude, por não considerarem este núcleo vital, “duro”, energético, chamado de moratória vital - advinda de um "capital vital", de uma disponibilidade de energia, de vitalidade e mesmo de tempo de vida maiores, dos jovens, em relação aos adultos e velhos.

Não necessariamente as duas moratórias estão acopladas, ainda que esta seja uma tendência ou um desejo. A moratória vital, presente em jovens de todas as camadas sociais, no caso das camadas populares pode não vir acompanhada do reconhecimento da moratória social: seriam estes os "jovens não juvenis”. A manutenção da condição da moratória social, acompanhada de signos que ostentam uma suposta juventude, pode acontecer com pessoas que já estão com baixa moratória vital: seriam os "não jovens juvenis". Os "não jovens juvenis" tratam-se de um fenômeno cada vez mais comum em nossa contemporaneidade, em que os signos do mundo do consumo estão saturados do apelo à juvenilidade, em que se concebe uma velhice vivida de modo "juvenil" (DEBERT, 1999) - como uma "Terceira Idade", em que se pode adotar até mesmo em um final de semana, ou em um período de férias, a identidade juvenil adormecida na mente do adulto com fartos recursos financeiros.

Segundo Peregrino (2011), a concepção inicial de moratória social ou 


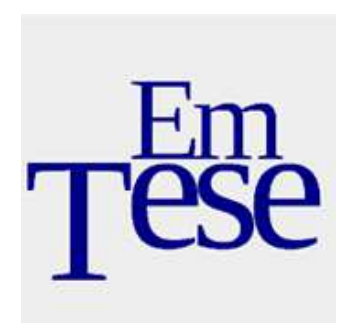

psicossocial não se preocupava com as clivagens de classe e enfatizava a unidade das juventudes. Por sua vez, a corrente classista dos estudos sobre juventude colocou estas clivagens acima da unidade geracional - Bourdieu (1983) chegou ao ponto de negar a validade da categoria juventude para a análise sociológica. Neste sentido, a proposição de Margulis e Urresti (1996) é um interessante meio termo. Se eles afirmam, à semelhança de Mannheim, que a juventude é uma posição ou situação social - ou seja, uma realidade social efetiva, construída e reconhecida socialmente na modernidade via a moratória social, também dizem que esta posição é vivida desigualmente pelos sujeitos. Àquela moratória vital do jovem, que lhe é naturalmente dada, mas que precisa ser cultural e socialmente significada para se efetivar, a sociedade pode (ou não) acrescentar outra reserva, excedente ou crédito, agora de caráter social: a dita moratória social. Trata-se de um "tempo doado" pela sociedade para os jovens experimentarem a condição adulta, dando-lhes certa autonomia para "configurar trajetórias de inscrição social" (PEREGRINO, 2011, p. 281). Mas este tempo varia de acordo com condição social dos sujeitos, oscilando do alongamento indefinido à recusa.

Este "tempo doado" é também uma "postergação sustentada pela sociedade e por suas instituições" das responsabilidades típicas de um adulto. A moratória social, portanto, não é apenas variável, mas também ambígua, pois esta postergação, como já anunciara Bourdieu, afasta os jovens dos "jogos sociais de poder" e adia sua autonomia plena, ficando sob o controle das gerações mais velhas este processo de transição do jovem à posição social de adulto (PEREGRINO, 2011, p. 282).

\section{Cultura, classe e juventude}

A "corrente classista" no interior da sociologia da juventude, nos termos de Pais (1993), componente do que aqui chamo de teorias críticas, relativiza bastante o valor das gerações e dos grupos juvenis nas sociedades cravejadas pela desigualdade de classes sociais. Mais caracteristicamente, como o Centro de Estudos Culturais 


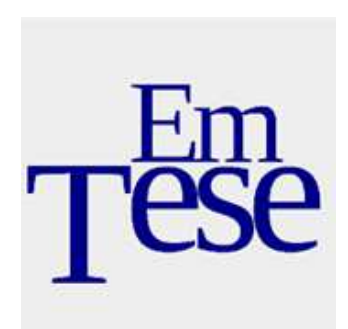

Contemporâneos, da Universidade de Birmingham, combina o vetor etário e geracional com a determinação da estrutura de classes. No limite, como em já comentado texto de Pierre Bourdieu, nega validade sociológica à noção de juventude.

A segunda metade do século XX, ao menos até meados da década de 1970, ficou marcada como a Era Dourada da economia mundial (HOBSBAWM, 1995). Segundo Abramo (1994), é o tempo do auge do Estado de Bem-Estar na Europa, da afluência nos países ricos e mesmo nos que estariam "em desenvolvimento". O tema do jovem consumidor de mercadorias no tempo de lazer (lanchonetes, rock'n'roll, programas de auditório, refrigerantes, chiclets, motocicletas etc.) enseja a ideia de um ampla e internacional cultura juvenil, inclusive "extra-classe", que se impunha contra antigas representações, típicas do estrutural-funcionalismo e de parte da Escola de Chicago: as subculturas juvenis marginais (das gangues "desviantes”) ou restritas (dos adolescentes nas escolas de ensino médio).

As formas culturais assumidas pelos grupos juvenis britânicos, nos anos 1950, foram tomadas por alguns analistas como exemplos desta cultura juvenil universal, irrompedora de barreiras de classe social, já que teddy boys dos subúrbios londrinos, depois skinheads, mods e rockers, faziam uso da música dita internacional da juventude, o rock'n'roll, e artigos de consumo típicos das classes médias para montar seus estilos espetaculares. Mas, como atenta Helena Abramo (1994), o Centro de Estudos Culturais Contemporâneos da Universidade de Birmingham, na Inglaterra, vai tomar justamente estes exemplos para se contrapor à tese da cultura juvenil universal.

A obra organizada por Stuart Hall e Tony Jefferson, Resistance through Rituals, publicada originalmente em 1976, é o grande marco da "corrente classista" da sociologia da juventude e dos estudos culturais de Birmingham (HALL; JEFFERSON, 1982). Há capítulos teóricos - tratando dos conceitos de cultura, subcultura e estilo, entre outros -, capítulos oriundos de estudos de caso - sobre os teddy boys, mods, skinheads, rastafaris e hippies, sobre a black music e a relação das jovens com as subculturas, entre outros - e capítulos sobre metodologia de pesquisa, destacando a 


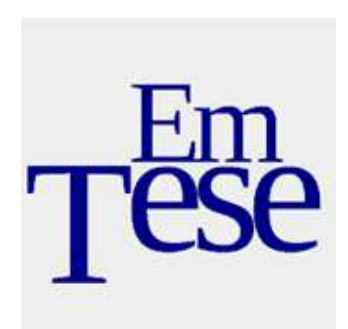

etnografia.

Apesar de representativo da corrente classista, é uma obra paradoxal, por fazer uso de um referencial teórico normalmente usado para refutar a perspectiva sociológica fundada nas categorias etárias e gerações, o marxismo. Mas se trata de uma leitura do marxismo que valoriza a dimensão cultural e, não à toa, Antonio Gramsci é uma importante referência. O estudo deseja flagrar uma forte relação entre as culturas juvenis, em destaque aquelas espetaculares citadas acima, com a luta de classes, especificamente o âmbito cultural e ideológico da luta pela hegemonia. Se reconhece a dimensão etária e geracional, entretanto, esta, assim como a dimensão cultural, é subsumida à determinação socioeconômica advinda da estrutura de classes sociais, ainda que em uma análise elegante e complexa.

O Centro de Estudos Culturais, nesta obra, elegeu como principal objetivo refutar a existência de uma cultura juvenil universal e, principalmente, "extra-classe". As "subculturas juvenis" cultivadas pela maioria dos grupos estudados, como os teddy boys, skinheads e mods, derivariam primordialmente da cultura de classe de origem dos membros destes grupos, a saber, a classe trabalhadora britânica. O termo "subculturas" ainda lembra o tom dos estudos estrutural-funcionalistas, mas aqui adquire teor bem distinto. Subculturas juvenis são modos de elaboração e respostas culturais dos jovens que fazem parte de dada classe, portanto, filiam-se à cultura de sua classe e às condições vividas por esta classe. Entretanto, como diferencial do modo como a cultura de classe é vivida pelos adultos, a subcultura juvenil carrega uma resposta peculiar destes jovens, dada sua posição etária e geracional.

No caso dos jovens operários ingleses, por um lado, as subculturas têm a ver com as condições mais gerais do operariado, tratam-se da resposta às transformações vividas pela classe operária no pós-guerra, que segmentaram e fragmentaram mais esta classe (opondo trabalhadores qualificados a menos qualificados, bem como nacionais e imigrantes) e diminuíram a solidariedade e identidade de classe (com as transformações dos bairros operários e a política conciliatória ensejada pelo Partido Trabalhista e os 


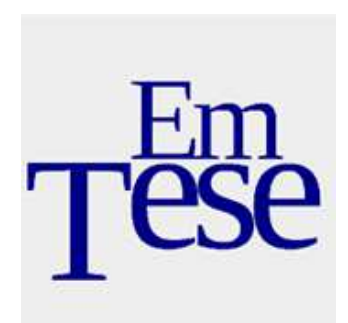

sindicatos). Por outro lado, as subculturas expressam dilemas que são próprios dos jovens desta classe social: entrar no estrato mais qualificado do operariado ou ficar entre os desqualificados; manter o puritanismo tradicional da classe ou adotar a nova ideologia de consumo. Diante do enfraquecimento das referências de classe, as subculturas indicam a busca de referenciais positivos para os jovens trabalhadores. Também se expressa a valorização dos espaços de lazer e diversão.

Nas subculturas juvenis da classe trabalhadora, os jovens reutilizam formas de adaptação, negociação e resistência vindas da cultura "matriz" operária. Juntam a estas formas, a apropriação de outros elementos culturais (como roupas, músicas, rituais, gírias e estilos de atuação), elementos vindos da cultura de massa, da cultura burguesa e até de antigas tradições operárias. Mas estes elementos de origem externa à cultura "matriz" operária são apropriados de modo peculiar, sendo ressignificados, em diferentes direções: os teddy boys, com roupas elegantes, afirmam a possibilidade de participar do mundo para além das fronteiras de classe; já os skinheads, vindos do operariado mais desqualificado, demonstram uma atitude defensiva do espaço e identidade de classe, afirmando valores como aspereza e machismo, com roupas e cabelos muito curtos, semelhantes aos dos antigos trabalhadores das docas e com atitude belicosa contra operários mais afluentes e imigrantes. As subculturas juvenis não são apenas "construções ideológicas", mas também meios para negociar espaços e sentidos no campo da luta pela hegemonia cultural. Ao mesmo tempo, expressam a busca de novos sentidos, valores e espaços aos jovens desta classe social. São formas de negociação e resistência diante da cultura dominante (CLARKE et al., 1982; CLARKE, 1982; ABRAMO, 1994).

Além das subculturas juvenis expressarem a condição da classe trabalhadora no pós-guerra e a posição peculiar dos jovens nesta classe, há a expressão da estrutura das relações entre os gêneros. As garotas estão menos presentes e aparecem menos nas subculturas, normalmente em posição secundária - em homologia com a posição subordinada da mulher na vida adulta da classe trabalhadora, vinculada à esfera da 


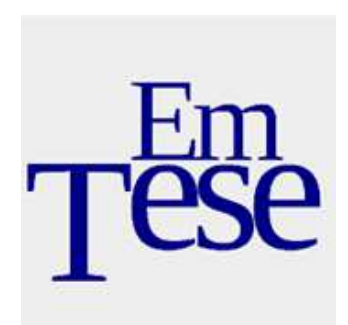

família e a atividades complementares no trabalho. A representação das subculturas juvenis na mídia e mesmo em algumas análises teóricas reforça também esta invisibilidade das garotas, ao enfatizar os valores masculinos das subculturas. Apesar de haver pequenos grupos femininos entre os teddy boys e os skinheads, apenas com os mods (estilo mais "leve") a participação feminina se torna mais expressiva (MCROBBIE; GARBER, 1982).

Há subculturas juvenis também nas classes médias, destacando-se, nos tempos de publicação de Resistance through Rituals, os hippies, os movimentos estudantis e a "cultura das drogas". Assim como as subculturas da classe operária fizeram, estas expressavam as contradições específicas da cultura "matriz" das classes médias no PósSegunda Guerra: mudanças estruturais como a proliferação dos "colarinhos brancos" e novas profissões, a expansão da educação, a afluência material etc. A tensão se exprime nos diferentes valores adotados pelos adultos de classe média (vinculados aos valores tradicionais desta classe) e pelos seus jovens integrantes da contracultura: estilo contra status, comunidade contra a família nuclear, anticapitalismo e antissindicalismo contra o pró-capitalismo, nomadismo contra a valorização do lar, "enclaves" em vez da área residencial, work-is-play ("trabalho como lazer") em vez da dicotomia lazer/trabalho, participação direta em vez da representação formal, ausência de liderança contra o elitismo, o público como pessoal contra a oposição cívico/privado, escolas livres ou deschooling (desescolarização) contra o sistema privado/público tradicional, "cena" versus clube, ideal da "vida é arte" contra a alta cultura, "butique" contra a alta moda, anticonsumo versus alto consumo, antimaterialismo contra materialismo, postura libertária contra a sobriedade, proposta de transcender os papéis em vez de se adaptar aos papéis, quebra dos papéis de gênero contra a oposição masculino/feminino (e domínio do masculino), individualismo fraternal contra individualismo possessivo. Os autores concluem que se tratava de mero desvio momentâneo de rota das classes médias, derivado da contraditória adaptação desta classe à nova configuração do capitalismo do Pós-Guerra (CLARKE et al., 1982). 


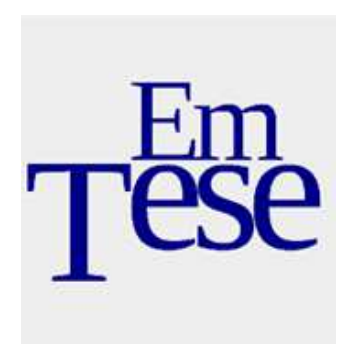

O Centro de Estudos Culturais fornece conceitos e perspectivas relevantes para pensar a relação entre juventude e estrutura de classes, e o faz dentro do campo da cultura. É um interessante exercício observar, contudo, que Resistance through Rituals traz elementos que podem configurá-la também como precursora das teorias "póscríticas" da juventude - assim como Silva (2010) vê nos estudos culturais da Universidade de Birmingham a origem de parte das teorias pós-críticas do currículo. Para tanto, faltaria afastar o mecanismo da determinação de classe, fortalecendo a noção de "estilo" e de ressignificação dos bens culturais, e abandonar a centralidade do papel da luta de classes pela hegemonia, em favor da autocriação de grupos juvenis e identidades. Reforçaria-se também a multiplicidade presente no subtítulo da obra, "subculturas juvenis", assim, no plural, presente no reconhecimento dos diversos caminhos possíveis, dentro de uma mesma classe social, para se criar um "estilo". Também, presente no reconhecimento de que não apenas a estrutura de classes condiciona a criação de subculturas, mas também o gênero e até a nacionalidade e a vinculação étnica. Há mesmo um autor que está presente nos dois momentos dos estudos culturais: Stuart Hall - um dos organizadores de Resistance through Rituals e coautor de importante capítulo teórico desta obra (CLARKE et al., 1982). Mais tarde, Hall aproximaria os estudos culturais do pós-estruturalismo e do pós-modernismo, afastando-se do marxismo cultural (HALL, 2006).

Em sentido diverso, Resistance through rituals por vezes se aproxima da negação da própria noção de juventude e geração. São momentos em que o marxismo é mais marcante, especialmente no capítulo destinado a criticar o uso ideológico e mercadológico de juventude, de Murdock e McCron (1982). Segundo eles, o uso ideológico do termo juventude, para neutralizar a consciência de classe, tem origem na classe média vitoriana, já antes da década de 1850, com o novo ethos criado por novas escolas e revistas - de início, limitado à classe média. Logo, revaloriza-se também o patriotismo, tendo o socialismo e a Alemanha como as grandes ameaças a derrotar, por meio da criação de agências como a Boys Brigade e os Escoteiros de Baden Powell. Na academia, Ortega y Gasset e, mais tarde, Karl Mannheim contribuem para uma 


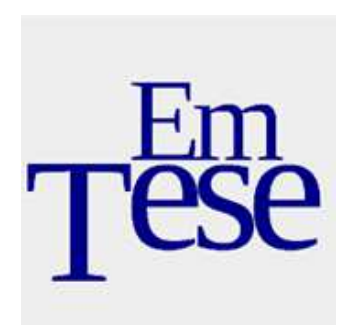

concepção destinada a neutralizar o valor da classe e da luta de classes como agentes históricos. O lugar seria ocupado pela geração e pela juventude.

Mas a mais contundente negação do valor sociológico da juventude não veio de marxistas. Para Bourdieu (1983) a "juventude é apenas uma palavra", pois ela é sobretudo um instrumento de demarcação no espaço social. A ideia de juventude tem sido recorrentemente usada, e não apenas nos séculos mais recentes, para demarcar territórios que restringem o acesso a direitos ou privilégios. Tal ideia afirma que certos sujeitos, os "jovens", são incapazes de exercer certas prerrogativas sociais. Esta demarcação mantém privilégios para certos grupos, por serem seus membros considerados como "maduros". Também, a noção de juventude nega posições muito distintas na estrutura de classes, tentando escamotear a flagrante desigualdade entre jovens das classes médias e das classes trabalhadoras.

A resposta de Margullis e Urresti (1996) a Bourdieu, assim como outrora, diante da crítica à noção de moratória social, foi conciliadora: "a juventude é mais do que uma palavra". Ou seja, a juventude, ainda que seja uma representação simbólica, permeada de valores ideológicos, é também uma realidade social concreta. Ainda que fosse apenas um instrumento ideológico de demarcação, a juventude já seria algo real na vida social, algo que tem poder simbólico. Como já foi dito, mais recentemente, o termo juventude ganhou uma conotação bastante positiva, como "juvenilidade" (SANTOS, 1992), como padrão de corpo, estado de espírito e comportamento social a ser seguido inclusive por adultos e velhos (a "Terceira Idade").

Neste sentido, o termo juventude indica formas de ser e de se relacionar que são reais, ainda quando apenas imaginadas ou desejadas por distintas camadas sociais. Contudo, para além disto, os sociólogos argentinos Margulis e Urresti (1996) afirmam que, apesar de haver realmente uma diversidade de juventudes, há alguns princípios comuns que as norteiam.

Aqui é preciso retomar alguns argumentos trazidos nos itens anteriores, a respeito da geração e da moratória, dado que estes sociólogos mobilizam tais teses para 


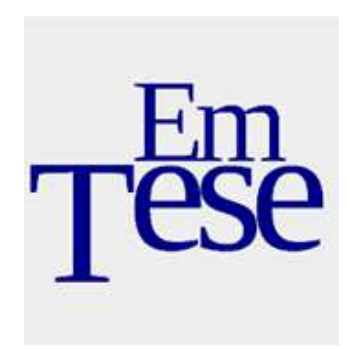

defender a concretude das juventudes nas sociedades modernas e contemporâneas, ou seja, para afirmar que a noção de juventude não é apenas engodo ideológico e publicitário. O primeiro princípio comum, que permearia as diversas juventudes seria a moratória social, como realidade ou desejo, conforme já discutido, ou seja, o direito a um período de experiências, a um tratamento mais tolerante em comparação com outras categorias etárias e ao adiamento de certas obrigações sociais (referentes ao trabalho, a constituir família e ter sua própria moradia). Segundo, a experiência geracional, como já afirmava Karl Mannheim, ou seja, que é toda uma geração que tende a passar por experiências históricas e sociais comuns, compartilhando tais experiências que podem possibilitar uma "unidade de geração" (uma forma comum de sentir o mundo e interpretar os fatos presentes, distinta do modo como fazem as gerações precedentes). Enfim, como terceiro elemento que tende a marcar a condição juvenil, a moratória vital, ou seja, uma maior disponibilidade de energia, vitalidade e tempo de vida do jovem em comparação com adultos e idosos (MARGULIS; URRESTI, 1996).

\section{Considerações finais}

As teorias críticas da juventude, em suas variantes geracional e classista, passíveis de retradução como vertentes reformista e revolucionária, foram marcantes na segunda metade do século XX. Elas criaram e recriaram importantes conceitos, como geração, moratória social e subculturas, e trouxeram novos temas, como conflito de gerações, movimentos juvenis, cultura e lazer. Estas teorias criticaram e ressignificaram aquelas concepções de juventude elaboradas pelas teorias tradicionais.

Primeiro, as teorias críticas valorizaram o potencial contestador da juventude, potencial que passou a ser visto como algo positivo, capaz de renovar as sociedades e permitir o avanço da civilização, e não mais como mero "desvio" ou "anormalidade".

Segundo, conceberam a juventude como tempo e momento para a experimentação de papéis sociais, com espaços, institucionalizados ou não, em que há 


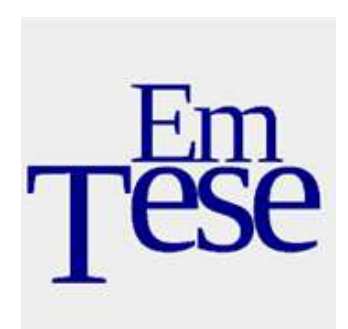

certo relaxamento das normas sociais em relação aos jovens - a moratória social.

Terceiro, avançaram no processo de "desnaturalização" da categoria juventude, aumentando a consciência sobre o caráter social e cultural desta categoria. Percebeu-se melhor o papel das instituições sociais (Estado, escola, legislação, mundo do trabalho, família etc.) na marcação das etapas do curso da vida e relativizou-se o caráter "natural" ou "biológico" das idades da vida - este caráter natural existe, mas sempre precisa ser ressignificado pela sociedade e cultura. Se Mannheim inicia este movimento, ainda que com limites, a corrente "classista" o reforçaria, chegando em alguns casos a negar validade sociológica à categoria juventude - entre os extremos, a percepção de que a possibilidade de viver a moratória social é limitada pela condição de classe, de gênero e étnica, entre outras, encaminhando as teorias críticas ao próximo ponto.

Quarto, as teorias críticas deram início ao reconhecimento da diversidade de vivências da juventude, de acordo com a classe social, o gênero, a etnia, a nacionalidade etc. do jovem em particular. A radicalização deste reconhecimento encaminharia parte da corrente "classista" às teorias pós-críticas da juventude.

Quinto, as teorias críticas acabariam por valorizar as chamadas subculturas juvenis, especialmente pelos estudos culturais - mais tarde, nas teorias pós-críticas, as subculturas são renomeadas como culturas, estilos, grupos, identidades, "tribos" etc. Valorizam-se cada vez mais as experimentações de pequenos coletivos e indivíduos que ressignificam ou transgridem a cultura e os valores sociais vigentes, muitas vezes dando origem a novos valores, comportamentos e bens culturais integrados ao mercado de consumo, mas podendo denotar um permanente estado de resistência ou criação transgressora.

Os anos 1970 iriam presenciar novas configurações daquelas subculturas juvenis e dos movimentos juvenis. Desde então, tanto como resposta quanto como potencializadora da nova e complexa situação, a sociologia da juventude passa a desenvolver novas teorias, as teorias pós-críticas. As concepções sociológicas de juventude, focadas tradicionalmente na socialização e criticamente na capacidade de 


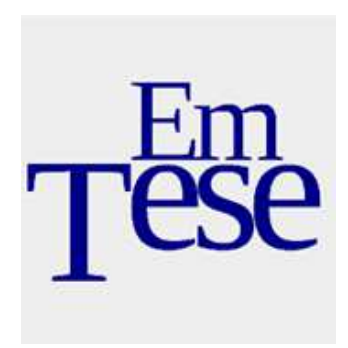

renovação, implodem. A sociologia da juventude tenta viver dos cacos colhidos por suas reflexões e pesquisas. Mas estes são temas para novos desenvolvimentos.

\section{Referências}

ABRAMO, Helena Wendel. Cenas juvenis: punks e darks no espetáculo urbano. São Paulo: Scritta, 1994.

BAUDRILlARD, Jean. Para uma crítica da Economia Política do signo. São Paulo: Martins Fontes, 1972.

BOURDIEU, Pierre. “A 'juventude' é apenas uma palavra”. In: BOURDIEU, Pierre. Questões de sociologia. Rio de Janeiro: Marco Zero, 1983, p. 112-121. Homo Academicus. Paris: Minuit, 1984.

CLARKE, John et al. "Subcultures, cultures and class". In: HALL, Stuart \& JEFFERSON, Tony (orgs.). Resistance through rituals. Youth and subcultures in postwar Britain. Londres: Hutchinson, Birmingham: Universidade de Birmingham, 1982, p. 9-74.

CLARKE, John. "Style". In: HALL, Stuart \& JEFFERSON, Tony (orgs.). Resistance through rituals. Youth and subcultures in post-war Britain. Londres: Hutchinson, Birmingham: Universidade de Birmingham, 1982, p. 175-191.

COLEMAN, James S. The adolescent society. The social life of the teenagers and ist impact on Education. Nova Iorque: Macmillan Company, 1961.

DEBERT, Guita Grin. A dissolução da vida adulta e a juventude como valor. Horizontes Antropológicos. Porto Alegre, ano 16, n. 34, jul./dez 2010, p. 49-70.

A reinvenção da velhice: socialização e processos de reprivatização do envelhecimento. São Paulo: Editora da Universidade de São Paulo; Fapesp, 1999.

ERIKSON, Erik. Childhood and Society. Nova Iorque: W.W. Norton, 1978. 


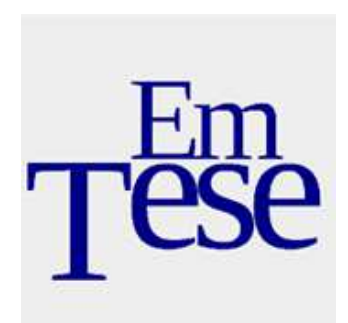

ERIKSON, Erik. Sociedade y adolescencia. 11a ed. México: Siglo Veintiuno, 1987.

EISENSTADT, S. N. De geração a geração. São Paulo: Perspectiva, 1976.

FURTER, Pierre. Juventude e Tempo Presente. Paz e Terra: Rio de Janeiro, 1967.

GENNEP, Arnold von. Os ritos de passagem. 3a ed. Petrópolis: Vozes, 2011.

GOODMAN, Paul Problemas de la juventude en la sociedade organizada.Barcelona: Península, 1971.

GROPPO, Luís Antonio. Autogestão, universidade e movimento estudantil. Campinas: Autores Associados, 2006.

HALL, G. Stanley. Adolescence: Its Psychology and Its Relations to Physiology, Anthropology, Sociology, Sex, Crime, Religion and Education. $2^{\text {a }}$ ed. New York: D. Appleton and Company, 1937.

HALL, Stuart. A identidade cultural na pós-modernidade. 11a ed. Rio de Janeiro: DP\&A, 2006.

HALL, Stuart \& JEFFERSON, Tony (orgs.). Resistance through rituals. Youth and subcultures in post-war Britain. Londres: Hutchinson, Birmingham: Universidade de Birmingham, 1982.

HOBSBAWM, Eric. Era dos Extremos. O breve século XX. 1914-1991. São Paulo: Cia. das Letras, 1995.

HOBSBAWM, Eric. “Maio de 1968”. In: HOBSBAWM, Eric. Revolucionários. Ensaios contemporâneos, Rio de Janeiro: Paz e Terra, 1982, p. 235-244.

KRAUSKOPF, Dina. Comprensión de la juventud. El ocaso del concepto de moratoriapsicosocial. JOVENes. Revista de Estudios sobre la Juventud. México, 2004, ano 8 , n. 21, p. 26-39.

MAFFESOLI, Michel. O tempo das tribos. O declínio do individualismo nas sociedades de massa. Rio de Janeiro: Forense-Universitária, 1987. 


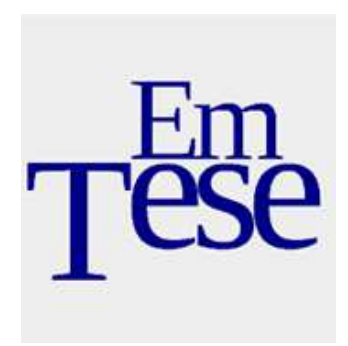

MANNHEIM, Karl. "O problema sociológico das gerações”. In: FORACCHI, Marialice M. (org.). Mannheim. Col. Os Grandes Cientistas Sociais, n. 25, São Paulo: Ática, 1982, p. 67-95.

MANNHEIM, Karl. "O problema da juventude na sociedade moderna”. In: BRITTO, Sulamita de. (org.). Sociologia da juventude. Vol. I, Rio de Janeiro: Zahar, 1968, p. 6993.

MANNHEIM, Karl. Diagnóstico de nosso tempo. Rio de Janeiro: Zahar, 1961.

MARGULIS, Mario; URRESTI, Marcelo. "La juventude es más que uma palavra”. In: MARGULIS, Mario (editor). La juventude es más que uma palavra. Buenos Aires: Biblos, 1996, p. 13-30.

McROBBIE, Angela; GARBER, Jenny. "Girls and subcultures”. In: HALL, Stuart \& JEFFERSON, Tony (orgs.). Resistance through rituals. Youth and subcultures in postwar Britain. Londres: Hutchinson, Birmingham: Universidade de Birmingham, 1982, p. 209-222.

MORIN, Edgar. Cultura de massas no século XX: o espírito do tempo. Vol. I - Neurose. 2a ed. Rio de Janeiro: Forense Universitária, 1986

MURDOCK, Grahan \& McCRON, Robin. "Consciouness of class and consciouness of generation”. In: HALL, Stuart \& JEFFERSON, Tony (orgs.). Resistance through rituals. Youth and subcultures in post-war Britain. Londres: Hutchinson, Birmingham: Universidade de Birmingham, 1982, p. 192-207.

NATANSON, Jacques-J. Les éducaeurs à l'épreuve. Esprit. n. 374, Paris, 1968, p. 313328.

PAIS, José Machado. Culturas juvenis. Lisboa: Imprensa Nacional, 1993.

PARSONS, Talcott. A classe como sistema social. In: BRITTO, Sulamita de (org.). Sociologia da juventude. vol. III. Rio de Janeiro: Zahar, 1968, p. 47-76.

PEREGRINO, Mônica. "Juventude, trabalho e escola: elementos para análise de uma 


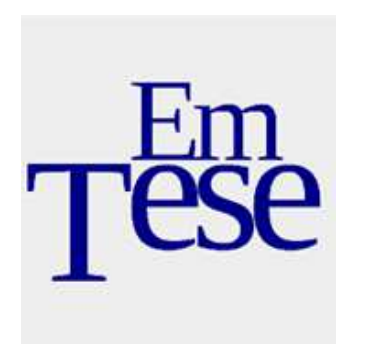

posição social fecunda". Cadernos Cedes. Campinas, 2011, v. 31, n. 84, p. 275-291, Disponível em:< http://www.scielo.br/pdf/ccedes/v31n84/a07v31n84.pdf>. Consultado em: 20/out./2013.

SALLAS, Ana Luisa Fayet; BEGA, Maria Tarcisa Silva. "Por uma Sociologia da Juventude - releituras contemporâneas". Política \& Sociedade: Revista de Sociologia Política. v. 5, n. 8, 2006, p. 31-58. Disponível em: $<$ https://periodicos.ufsc.br/index.php/politica/article/view/1803>. Acesso em: 25 de fev. de 2013.

SANTOS, Rafael. A publicidade e a representação da juventude. Dissertação (Mestrado em Antropologia Social), Instituto de Filosofia e Ciências Humanas da Universidade Estadual de Campinas, Campinas, 1992.

SILVA, Tomaz Tadeu da. Documentos de identidade: uma introdução às teorias do currículo. 3a ed. Belo Horizonte: Autêntica, 2010.

SOUSA, Janice Tirelli Pont de. Apresentação do dossiê. A sociedade vista pelas gerações. Política \& Sociedade: Revista de Sociologia Política. Florianópolis, 2006, v. 5, n. $8, \quad$ p. 9-30. Disponível em: $<$ https://periodicos.ufsc.br/index.php/politica/article/download/1802/1561>. Acesso em: 10 de mar. de 2013. 


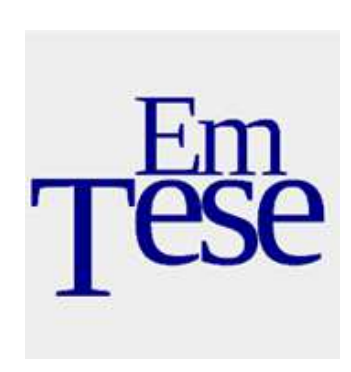

\title{
Teorias críticas da juventude: geração, moratória social e subculturas juvenis
}

Resumo: O artigo propõe a noção de teorias críticas da juventude para analisar importantes concepções de juventude formuladas na segunda metade do século XX, que tiveram influência para além dos meios acadêmicos e são até hoje presentes, tais como moratória social, gerações e subculturas juvenis. Por meio de revisão bibliográfica, analisa-se a constituição destas concepções de juventude e suas características principais. O traço crítico destas teorias reside no reconhecimento do potencial papel socialmente transformador das juventudes, em versões moderadas ou mais radicais. Elas avançam em relação às teorias anteriores de juventude, aqui chamadas de tradicionais, por conceber de modo mais positivo as dissidências e revoltas dos grupos juvenis. Mas ainda são influenciadas pelas concepções tradicionais de juventude, em especial a noção "clássica" de socialização que a concebe como uma integração de crianças e jovens na sociedade, orientada de modo unilateral pelos adultos.

Palavras-chave: Sociologia da Juventude. Geração. Moratória Social. Subculturas Juvenis. Teorias Críticas.

\section{Critical theories of youth: generation, social moratorium and youth subcultures}

\begin{abstract}
The article proposes the notion of critical theories of youth to analyze important youth conceptions formulated in the second half of the twentieth century, such as social moratorium, generations and youth subcultures. Through literature review, analyzes the constitution of these youth and their main features conceptions. The critical feature of these theories lies in the recognition of the potential socially transformative role of youths in moderate or more radical versions. Critical theories advance over traditional to design more positively dissent and revolt of youth groups, not simply interpreted as a deviation or abnormality. But they are still influenced by traditional conceptions of youth, in particular the "classic" notion of socialization, that conceives it as an integration of children and young people in society, driven unilaterally by adults.
\end{abstract}

Keywords: Sociology of Youth. Generation. Social Moratorium. Youth Subcultures. Critical Theories. 


\section{Tese}

Recebido em: 26 de março de 2015

Aceito para publicação em: 13 de maio de 2015 